
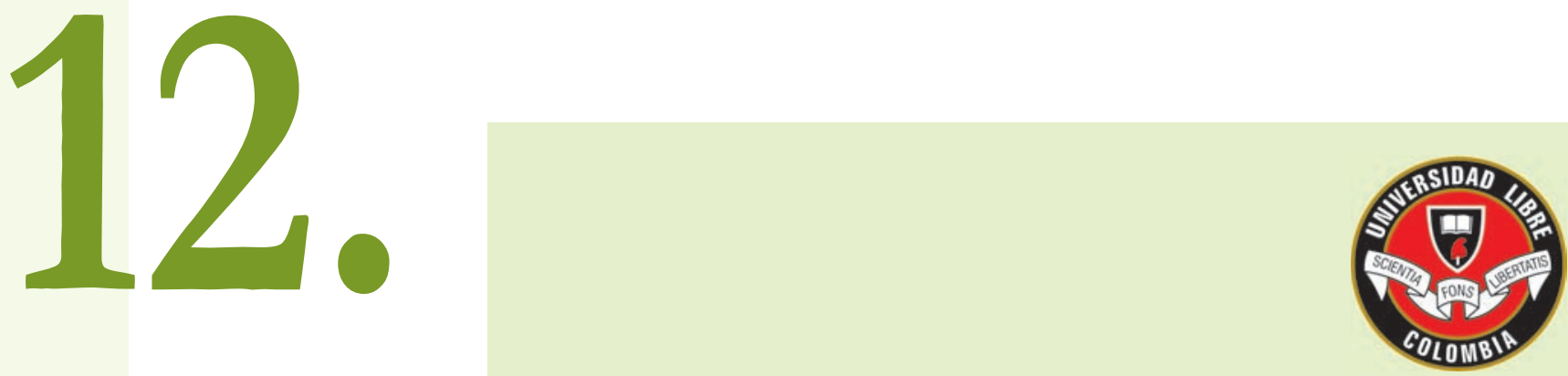

La Calidad Académica, un Compromiso Institucional

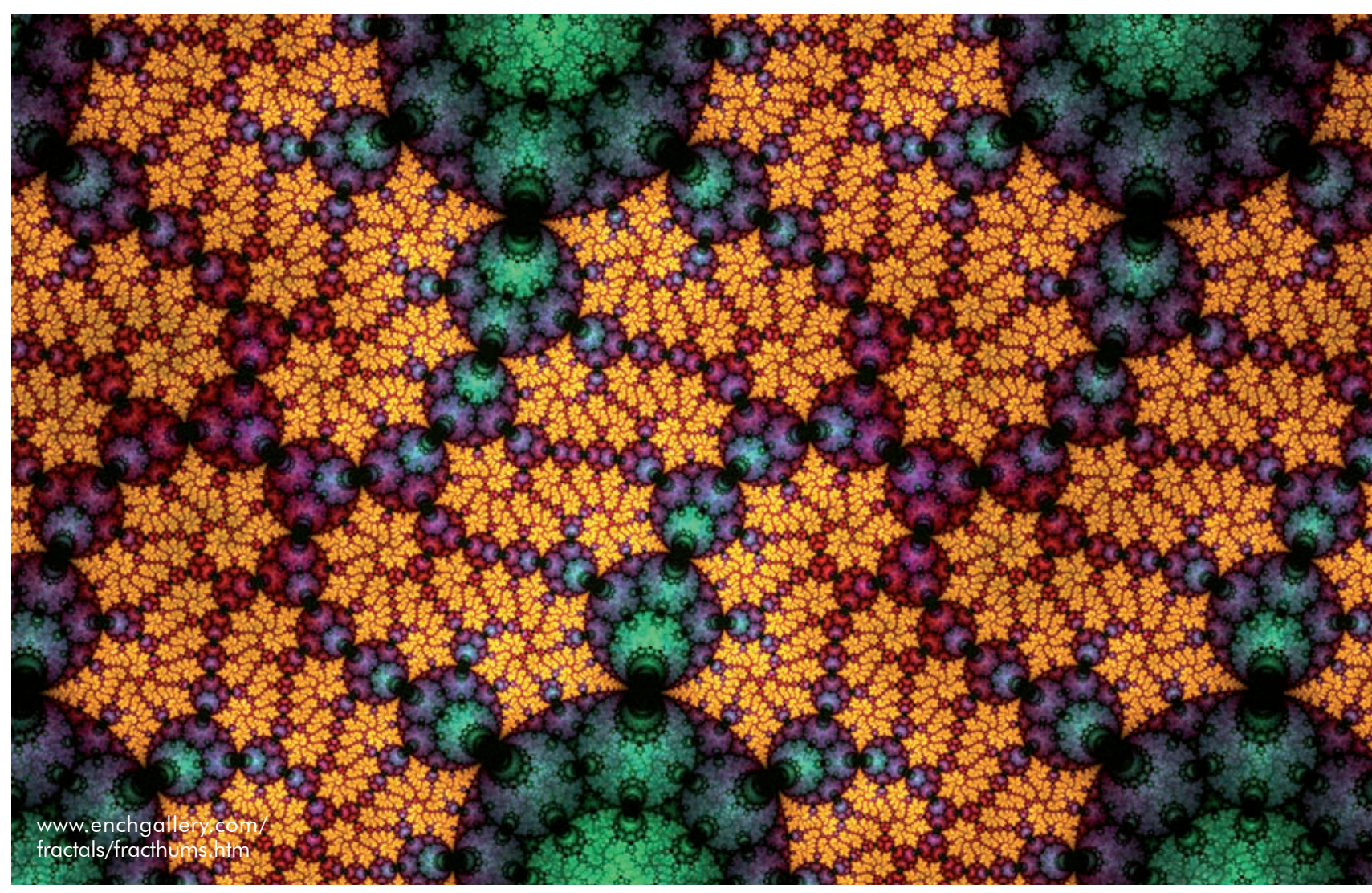

Avellaneda B., Campo A. y Ortiz B., José J. (2012). Explicación contamétrica de las dinámicas patrimoniales desde una concepción social. Criterio Libre, 10 (17), 259-286 ISSN 1900-0642

Explicación contannétrica de las dinámicas patrimoniales desde una concepción social Campo Alcides Avellaneda Bantista José Joaquín Ortiz Bojacá 


\section{EXPLICACIÓN CONTAMÉTRICA DE LAS DINÁMICAS PATRIMONIALES DESDE UNA CONCEPCIÓN SOCIAL"}

\section{CAMPO ALCIDES AVELLANEDA BAUTISTA JOSÉ JOAQUÍN ORTIZ BOJACÁ}

\footnotetext{
Artículo de investigación correspondiente a la linea de contametría, del grupo de investigación Constructores Contables, de la Universidad Libre, Bogotá, Colombia.

This article belongs to the Constuctores Contables Countermetrics Research line of the
} Libre University, Bogotá, Colombia.

Artigo de pesquisa correspondente à linha de contametria, do grupo de pesquisa Construtores Contábeis, da Universidade Libre, Bogotá, Colômbia.

Document correspondant à la ligne de recherche contametría, Groupe de Constructeurs en Comptabilité, Université Libre (Bogota, Colombie).

₹ Magíster en Educación, especialista en Ciencias Tributarias, especialista en Revisoría Fiscal; profesor investigador del grupo de investigacion Constructores Contables, de la Facultad de Ciencias Económicas, Administrativas y Contables, de la Universidad Libre, Bogotá, Colombia. campoa.avellanedab@unilibrebog.edu.co

Master in Education, Tax Science Specialist, Tax Controller Specialist, Research Professor of the Libre University Economic Science Faculty Constructores Contables Research Group. Bogotá, Colombia. campoa.avellanedab@unilibrebog.edu.co

Mestre em Educação, especialista em Ciências Tributárias, especialista em Revisoria Fiscal; professor e pesquisador do grupo de pesquisa Construtores Contábeis, da Faculdade de Ciências Econômicas, Administrativas e Contábeis, da Universidade Libre, Bogotá, Colômbia.campoa.avellanedab@unilibrebog.edu.co

Master en éducation, spécialiste en impôts et réviseur comptable. Rechercheur du groupe Constructeurs en Comptabilité . Faculté des sciences économiques, gestion et comptabilité, Université Libre (Bogotá, Colombie).campoa.avellanedab@unilibrebog.edu.co

§ Magíster en Ciencias financieras y de sistemas, especialista en sistemas, profesor investigador del grupo de investigación Constructores Contables, de la Facultad de Ciencias Económicas, Administrativas y Contables, de la Universidad Libre, Bogotá, Colombia.Jjoaquin.ortiz@gmail.com

Masters in Financial and System Science, Professor of the Universidad Libre Economic Science Faculty Constructores Contables Research Group. Bogotá, Colombia. Jjoaquin. ortiz@gmail.com

Mestre em Ciências financeiras e de sistemas, especialista em sistemas, professor pesquisador do grupo de pesquisa Construtores Contábeis, da Faculdade de Ciências Econômicas, Administrativas e Contábeis, da Universidade Libre, Bogotá, Colômbia. Jjoaquin.ortiz@gmail.com

Master en sciences financiers Rechercheur du groupe Constructeurs en Comptabilité . Faculté des sciences économiques, gestion et comptabilité, Université Libre (Bogotá, Colombie).Jjoaquin.ortiz@gmail.com

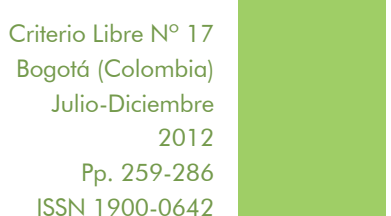




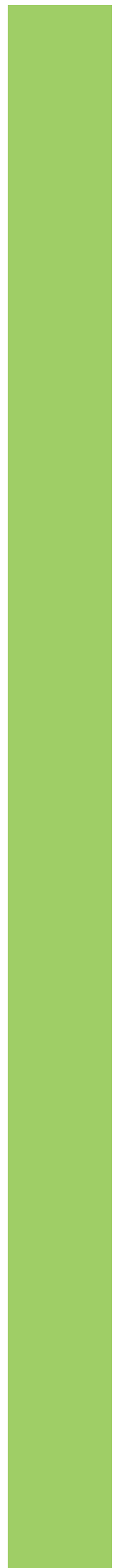

Fecha de recepción: mayo 20 de 2012 Fecha de aceptación: octubre 10 de 2012

Reception Date: May 202012 Acceptance Date: October 102012

Data de recepção: 20 de maio de 2012 Data de aceitação: 10 de outubro de 2012

Reçu le: 20 mai 2012 Accepté: Octobre 10, 2012

\section{RESUMEN}

Partiendo del concepto de que la contametría mide y valora el patrimonio y que este es la representación de la riqueza de los agentes sociales, este trabajo propone la explicación contamétrica de las dinámicas patrimoniales desde una concepción social. Es necesario explicar estos fenómenos para fines de la formalización y difusión de la contametría y para el avance en el estudio de la contabilidad como ciencia del patrimonio. Pero además, aporta a la gestión contable y administrativa, provee herramientas conceptuales para la justa y equitativa medida en la distribución de la riqueza, además de ampliar el horizonte de la investigación contable.

\section{PALABRAS CLAVE:}

Agentes sociales, contabilidad, contametría, dinámicas patrimoniales, epistemología contable.

\section{CLASIFICACIÓN JEL:}

C10, D10, M40, M49.

Countermetrics measure and value patrimony as a representation of wealth in social agents. This work proposes the countermetrical explanation of patrimonial dynamics from a social conception. It is necessary to explain this in order to formalize and diffuse countermetrics, as well as to make a breakthrough in the study of accounting as a science of patrimony. Countermetrics also contribute to accounting and administrative management. It provides conceptual tools for a fair measurement of the distribution of wealth, and widens the horizon of accounting investigation.

Key words: Social agents, accounting, countermetrics, patrimonial dynamics, accounting epistemology. JEL Classification: C10, D10, M40, M49. 
Partindo do conceito de que a contametria mede e avalia o patrimônio e que este é a representação da riqueza dos agentes sociais, este trabalho propõe a explicação contamétrica das dinâmicas patrimoniais a partir de uma concepção social. É necessário explicar estes fenômenos para fins da formalização e difusão da contametria e para o avanço no estudo da contabilidade como ciência do patrimônio. Além do mais, contribui à gestão contábil e administrativa, provê ferramentas conceituais para a justa e equitativa medida na distribuição da riqueza, além de ampliar o horizonte da investigação contábil.

Palavras chave: Agentes sociais, contabilidade, contametria, dinâmicas patrimoniais, epistemiologia contábil. Classificação JEL: C10, D10, M40, M49.

RÉSUMÉ

Basé sur le concept de contametria qui mesure et évalue le patrimoine et qui est la représentation de la richesse sociale, le présent document propose I'explication dynamique d'une conception sociale. Il est nécessaire d'expliquer ces phénomènes pour la formalisation et la diffusion de la contametria et ainsi pour le progrès dans l'étude de la comptabilité en tant que science.

En plus la contrametria contribue à la gestion comptable et administrative, fournit des outils conceptuels pour mesurer la répartition équitable de la richesse, et élargit I'horizon de la recherche comptable.

Mots-clés: les partenaires sociaux, la comptabilité, la contametria, la dynamique économique, l'épistémologie de la comptabilité. Classification JEL: C10, D10, M40, M49.

\section{INTRODUCCIÓN}

En plena segunda década del siglo XXI, cuando la tecnología de la información y las comunicaciones se ha apropiado del mundo social, tecnológico e investigativo, se han profundizado las dudas sobre muchos aspectos del conocimiento. Es el caso del conocimiento contable, tan milenario como afectado por reduccionismo contrario a los beneficios de la interdisciplinariedad.

No obstante que, desde muchas ópticas la contabilidad ha sido reconocida como ciencia social aplicada, aún persiste una gran proporción de profesionales y especialmente expertos de otras ciencias, que no aceptan que se reconozca tal rango para la contabilidad, la cual, para algunos no va más allá de ser una técnica, para otros es un simple instrumento de 
otras disciplinas como las ciencias económicas, el Derecho o la administración. Esta forma de ver la contabilidad ha sido causa de su lento desarrollo epistemológico, asumiendo más un rol de movimiento por inercia que por dinámica científica, salvo contadas excepciones de estudios epistemológicos que han hecho avanzar la teoría contable.

La medición es uno de los temas que no han sido resueltos satisfactoriamente por las ciencias. La ciencia contable no es ajena a esta problemática y, dado que uno de sus objetivos es la medición de la riqueza representada en el patrimonio de los agentes sociales, para su equitativa administración y redistribución se requieren metodologías adecuadas, equitativas y científicas.

Si la contabilidad tiene por objeto el estudio de los fenómenos del patrimonio, si este representa la riqueza de los agentes sociales, y si uno de los objetivos de la contametría es la medición para la equitativa administración del patrimonio, entonces ¿̇de qué manera la contametría permite abocar bajo el método científico la interpretación y explicación de la dinámica patrimonial en una concepción social?
Se fijó como objetivo explicar las causas y los efectos de la dinámica social que determina el fenómeno patrimonial como acumulador de riqueza.

Como tareas se asumió en esta disertación:

- Explicar los conceptos de contametría, dinámica del patrimonio, el patrimonio como concepción social, agentes sociales.

- Explicar la manera como la contametría aborda la interpretación de la dinámica patrimonial desde una concepción social.

- Aportar argumentos para el debate contable.

La investigación se enmarca en la teoría neopatrimonialista, mencionada por Coelho (2004, p. 139)' citando a Antonio Lopes de Sá, de quien tomamos aquí para fundamentación el axioma de la prosperidad social, que dice:

"Cuando la suma de la eficacia de los patrimonios implica prosperidad racional de todas las células sociales, en régimen de armónica interacción, esto también implicará prosperidad social, lo que equivaldrá a la satisfacción de las necesidades materiales de la humanidad".

\section{HIPÓTESIS}

1) La contametría es un subcampo del conocimiento contable, cuya función principal es medir y valorar el patrimonio de los agentes sociales.

2) Los agentes sociales son actores que participan de la vida de un país, como productores económicos o no, con derecho a poseer patrimonio.
3) El patrimonio en movimiento es el que determina la eficacia que transforma, consume y crea riqueza para los agentes sociales y para la humanidad.

Se justificó realizar esta investigación para aportar elementos epistémicos que permitan la difusión y avance de la teoría contable, la armonización de sus elementos y el crecimiento de la disciplina.

Coelho da Rocha, Luiz Fernando (2004). Aportes sobre doctrina científica del neopatrimonialismo contable. Revista Internacional LEGIS de Contabilidad y Auditoría, № 20, Bogotá, diciembre de 2004. 
${ }^{66}$ La contametría puede utilizar los cuatro cuadrantes del plano cartesiano para bacer análisis de la dinámica de un patrimonio, para lo cual representaremos la estructura de los activos $A$ en el eje de las ordenadas, y las deudas $D$ en el eje de las abscisas; la ecuación patrimonial nos mostrará la situación en que se encuentra un patrimonio $P$ en un momento dado.'

\section{EL MÉTODO}

La contametría tiene múltiples métodos para hacer la medición y valoración del patrimonio. En la siguiente sección se explica el método general de análisis contamétrico.

\subsection{MÉTODO GENERAL DE ANÁLISIS CONTAMÉTRICO MULTIDIMENSIONAL}

En esta sección se explica el método general de análisis contamétrico, explicado por medio del plano cartesiano, a partir de la ecuación patrimonial, y fundamentado en la realidad patrimonial de los agentes sociales.

La contametría tiene por objeto la medición y valoración del patrimonio, definido este por el diccionario (Ed. Cultural, 1999, p. 192)² como:

"Conjunto formado por dos estructuras de diferente carácter, una económica, formada por bienes y derechos, denominado activo, y otra financiera integrada por las obligaciones, denominada pasivo".

La definición dada contiene tres variables constituidas por: patrimonio, activo y pasivo y cada una de ellas a su vez contiene $n$ variables internas que pueden modificar a las variables que las contienen y agrupan, a las que denominaremos variables principales. Con las variables principales haremos el análisis matemático en el plano cartesiano, para demostrar la multidimensionalidad de la contametría, lo cual, dicho sea de paso, constituye una de las grandes diferencias con la economía.

Para operarlas matemáticamente, identificaremos la variable pasivo con la letra D (de Deudas), la variable activos la identificaremos con la letra $\mathrm{A}$

2 Diccionario de Contabilidad y finanzas. Editorial Cultural S.A. Madrid - España, 1999. 
y la variable patrimonio la identificaremos con la letra P.

Ordenando las variables, tenemos que:

$A=$ activo

$D=$ deudas (o pasivos)

$\mathrm{P}=$ patrimonio

Con estas variables escribimos la conocida y generalmente aceptada ecuación del patrimonio:

\section{Gráfica 1. Ecuación del patrimonio.}

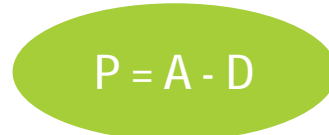

\subsection{ANÁLISIS \\ EN EL PLANO CARTESIANO}

La contametría puede utilizar los cuatro cuadrantes del plano cartesiano para hacer análisis de la dinámica de un patrimonio, para lo cual representaremos la estructura de los activos A en el eje de las ordenadas, y las deudas $D$ en el eje de las abscisas; la ecuación patrimonial nos mostrará la situación en que se encuentra un patrimonio $P$ en un momento dado, así:

a) En el cuadrante I (Gráfica 02) se analiza la existencia de un patrimonio (p) que está creciendo, o al menos está en estado estático, donde $p$ es igual a cero o mayor que cero. Es la situación normal, esperada en toda organización con ánimo de lucro o sin él.

Gráfica 2. Existe un patrimonio P, con $A>D$.

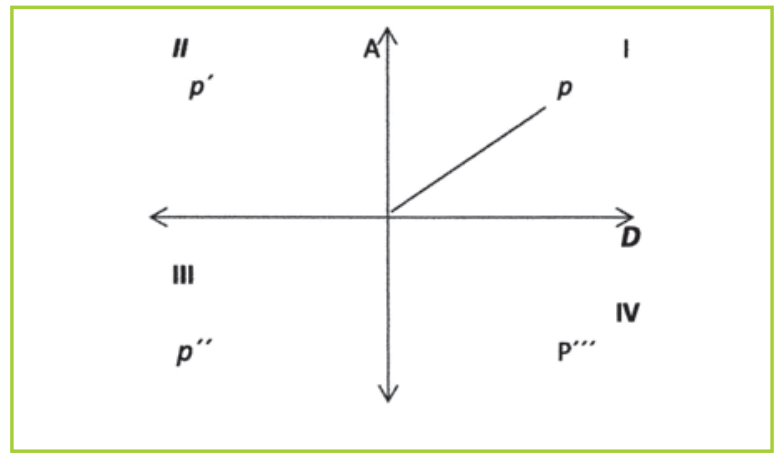

b) En el cuadrante (gráfica 03) se puede analizar la presencia de un patrimonio existente, pero pertenece a sujetos diferentes a su poseedor, es decir, $p^{\prime}$ resulta menor que cero, pero existen acreedores cuyos montos de deudas están respaldas de alguna manera (seguros o codeudores, otras garantías).

Gráfica 3. Existe un patrimonio $P$, con $A<D$.

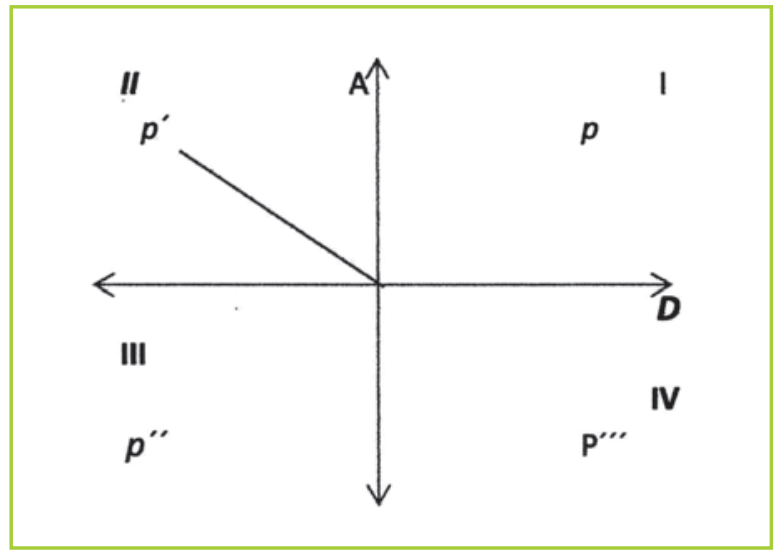

c) En el cuadrante III (gráfica 04) se puede analizar un patrimonio que existió, pero ya no existe; sin embargo, hay acreedores sobre el patrimonio que existió, y no hay respaldo de codeudores ni de seguros (caso de una empresa en liquidación en la que no solamente se perdió el patrimonio propio sino también el de los socios y acreedores) o no son suficientes. Es decir, $p^{\prime \prime}$ es menor que cero y valores de respaldo menores que cero.

\section{Gráfica 4. Se destruyó el patrimonio y no hay capacidad de pago porque: $[(-P)=(A<0)<D]$}

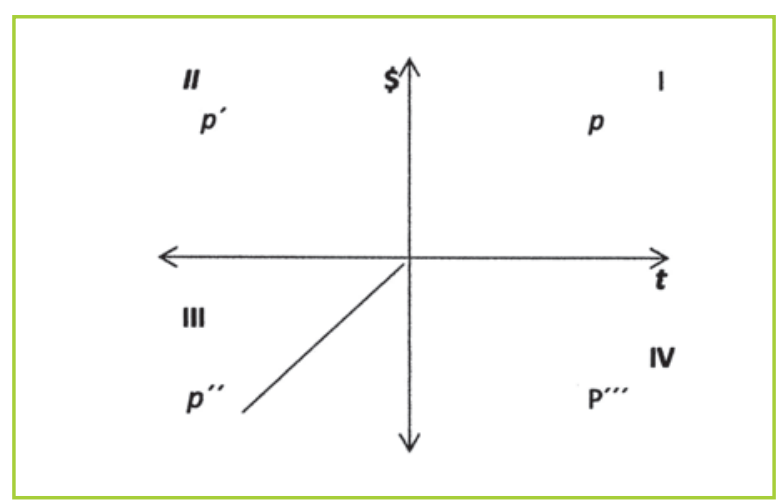


d) En el cuadrante IV (gráfica 05) se puede analizar un patrimonio que existió, $O$ es susceptible de existir, pero hay un patrimonio fuera del conjunto analizado que responde por la existencia pasada o futura del patrimonio analizado. Es el caso del patrimonio asignado formalmente pero que aún no está representado realmente, o ya existió y se perdió, pero puede ser recuperado $(r)$ o está amparado de alguna forma a sus acreedores. Es decir, $p^{\prime \prime}$ ' es menor o igual a cero, pero en el tiempo estará respaldado de alguna forma ante los acreedores.

Gráfica 5. No hay patrimonio pero existe la posibilidad de recuperar lo perdido porque:

$$
(-p)=\{[(A<0)<D]+r\}
$$

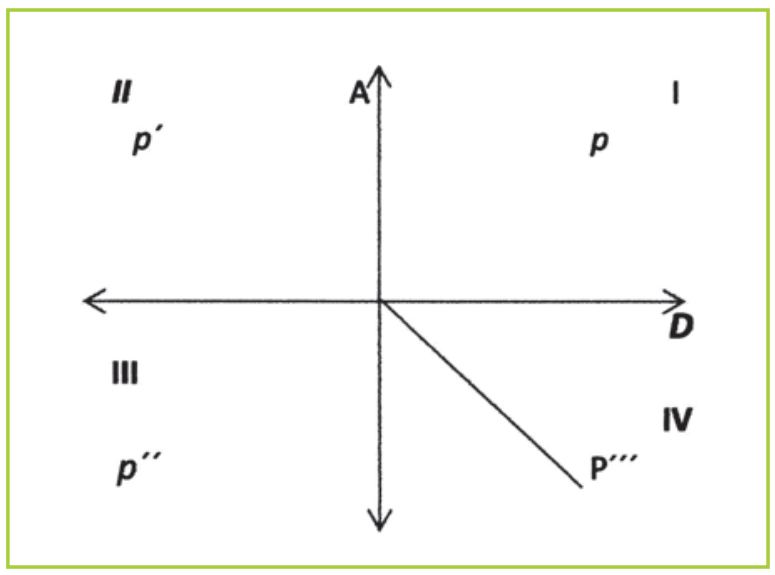

\subsection{REPRESENTACIÓN GENERAL}

A continuación se muestra en la Gráfica 6 la representación general del método contamétrico, con las cuatro situaciones antes descritas.

El modelo de análisis muestra que la contametría es multidimensional y este método contamétrico de análisis, al igual que lo hiciera el método económico, (Castaño, 1979, p. 14)³ es tomado de los modelos estadísticos y matemáticos con

\section{Gráfica 6. Representación gráfica del Método Contamétrico}

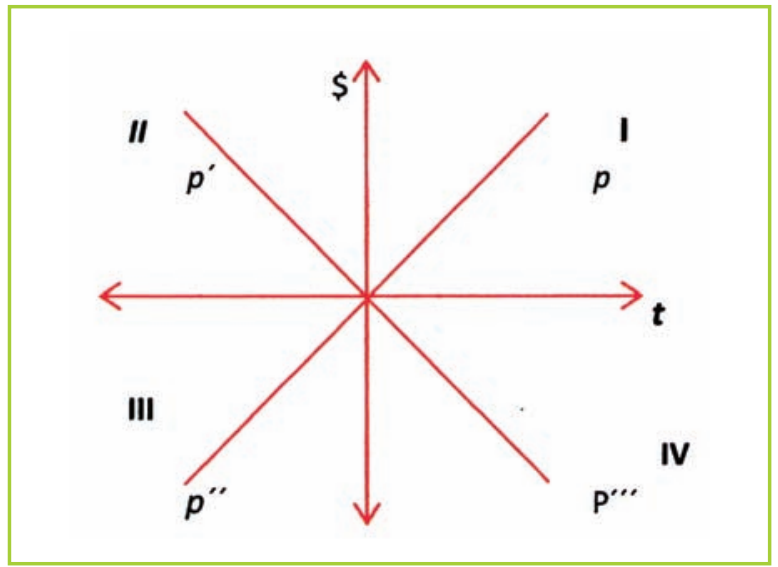

los que se desarrolló la econometría hacia la década de 1940, según lo describe Schmidt (2005, p. 1) ${ }^{4}$. Sin embargo, se diferencia del método económico porque aquel basa su análisis solamente en el cuadrante I del plano cartesiano (positivo-positivo), teniendo en cuenta que, según Castaño (1979, pp. 14, $15)^{5}$, el objeto de estudio de la economía "lo constituyen los bienes y servicios escasos, aptos para satisfacer necesidades", y hace el análisis con solo dos variables, de donde se desprende que los bienes o servicios solamente pueden tener magnitud cero, o mayor que cero. En contametría, las variables pueden tener valor mayor que cero, igual a cero o menor que cero, como se ve en las gráficas.

Para la contametría, su objeto de estudio es el patrimonio en su calidad de representación de la riqueza de los agentes sociales y esta riqueza, al existir, se puede representar, en primera instancia, igual que lo hace la ciencia económica, en el cuadrante l, positivo - positivo; pero puede ocurrir también (y aquí el método económico se aleja del método contamétrico), que aquella riqueza que en algún momento existió, se destruyó en desarrollo de su dinámica,

Castaño, Ramón Abel. Ideas económicas mínimas (1979). $8^{a}$ ed., Editorial Bedout, S.A., Medellín.

Schmidt, Stephen J. (2005). Econometría. Trad. de Pecina y Pineda, Editorial McGraw-Hill, México.

Castaño, op. cit. 
pero los agentes sociales que ostentaron la propiedad de dicha riqueza están en capacidad y en obligación de responder por el patrimonio destruido (perdido). En este caso, no obstante que se perdió el patrimonio, existe un intangible que es el derecho de los acreedores de cobrarse las deudas. Por esta razón se puede representar esta situación patrimonial en el cuadrante II, con un patrimonio mayor que cero, pero con la representación de la propiedad menor que cero, debido a que las deudas (D) son mayores que el patrimonio existente.

Pero si ocurre que no solamente se perdió el patrimonio de la organización (agente social de primer orden) sino que también se perdió la posibilidad de que el acreedor se cobre la deuda (agente social de segundo orden), ya sea por quiebra de quien ostentaba la propiedad del patrimonio perdido, o por otras razones, tal situación se puede representar en el cuadrante III (negativo-negativo), porque se perdió el patrimonio pero también se perdieron patrimonios ajenos a la organización, es decir, que el patrimonio es menor que cero y la posibilidad de recuperación igualmente sería menor que cero.

Finalmente, puede ocurrir que habiéndose perdido el patrimonio del agente de primer orden y habiéndose perdido también el patrimonio de quienes ostentaban la propiedad del patrimonio perdido, por diferentes (aunque escasas) causas, puede restablecerse la posibilidad de que tanto los acreedores como los propietarios del patrimonio perdido puedan recuperarlo, como sería el caso de un acuerdo de pagos. En este caso, la representación matemática estaría en el cuarto cuadrante, con un patrimonio menor que cero, pero con la posibilidad intangible de recuperar lo perdido en un futuro cercano o lejano.

\subsection{IMPORTANCIA Y UTILIDAD DEL MÉTODO}

La importancia de este método se ve reflejada en su utilidad para diagnosticar problemas (enfermedades) de las organizaciones y

\section{${ }^{66}$.El modelo de análisis}

muestra que la contametría

es multidimensional y este

método contamétrico de

análisis, al igual que lo

biciera el método económico

... es tomado de los modelos

estadísticos y matemáticos

con los que se desarrolló la

econometría hacia la década

de 1940." 
${ }^{6}$ La producción, como las inversiones, o la misma administración financiera, requiere la información contable y con base en ella, la contametría se encarga de hacer las mediciones correspondientes, tanto en magnitudes como en valores, en los que es necesario, además de las matemáticas, utilizar la berramienta estadística, como es el caso del uso de los promedios para la gestión de inventarios. entidades, pronosticar los resultados de la planeación de un patrimonio y en general, para la toma de decisiones tanto administrativas como financieras. Sirve a la administración, a los inversores, al Estado y al público en general y como herramienta evaluativa en los procedimientos de control (auditorias) y a los organismos de fiscalización.

\subsection{OBJETO E INSTRUMENTOS DE MEDICIÓN}

Partiendo del hecho de que la riqueza se representa en el patrimonio de los agentes sociales (axioma), los entes tangibles e intangibles allí representados son el objeto de la medición y la valoración contamétrica.

\subsection{SISTEMA GENERAL CONTAMÉTRICO}

Se sabe que el sistema de cuentas está constituido por un campo positivo (débito) y un campo negativo (haber).

- La cuenta en su sentido abstracto, conceptual y real, es el instrumento metodológico a través del cual se lleva a cabo el proceso de formación de los datos de medición y valoración.

- La cuenta es el principal instrumento de medición para la contametría.

- Las herramientas utilizadas en esta parte del proceso son las matemáticas (cálculo elemental) y en algunos casos la estadística.

- La cuenta como subsistema de la contabilidad, recibe la información generada por la acción de los agentes sociales.

- La información se acumula o desacumula en el sistema de cuentas, agrupando en forma depurada, la magnitud resultante (saldos), la cual constituye el producto o salida del sistema ya en forma de estados financieros o de otros informes.

- La representación de la realidad patrimonial son las magnitudes expresadas en unidades de medida, que pueden ser de naturaleza monetaria o no monetaria. 


\subsection{SISTEMAS PRODUCTIVOS}

En el proceso de transformación de bienes, además del sistema de cuentas, intervienen otros sistemas y procesos más complejos con los cuales se forman las redes del sistema contamétrico (tablas de acumulación de datos, reportes, órdenes de producción, indicadores de gestión, etc.), como lo explica Beltrán (1998, pp. 50 a 57) ${ }^{6}$.

En general, todas las relaciones costo-volumenutilidad se definen con base en la contametría, pues como dice Horngren (1969, p. 26) ", "uno de los principales objetivos de la contabilidad es la medición significativa de los resultados".

Esa medición es hecha por la contametría. Un ejemplo de su aplicación se muestra en el modelo 1.

El modelo se emplea para medir el punto de equilibrio por unidad de producción y se utiliza en la contabilidad de costos. Es un ejemplo de cómo se viene aplicando la contametría en los procesos de producción.

\subsection{LA PLANEACIÓN}

La producción, como las inversiones, o la misma administración financiera, requiere la información contable y con base en ella, la contametría se encarga de hacer las mediciones correspondientes, tanto en magnitudes como en valores, en los que es necesario, además de las matemáticas, utilizar la herramienta estadística, como es el caso del uso de los promedios para la gestión de inventarios (Gráfica 7).

\subsection{INTERDISCIPLINARIEDAD Y TRANSDISCIPLINARIEDAD}

El resumen del proceso de la organización lo determina el cuantum, el valor, y el precio de los bienes y servicios, y estos son determinados por la
Gráfica 7. Aplicación contamétrica en producción. MC.u $=$ V-c $[$ Con $\mathrm{c}=$ costo de ventas]

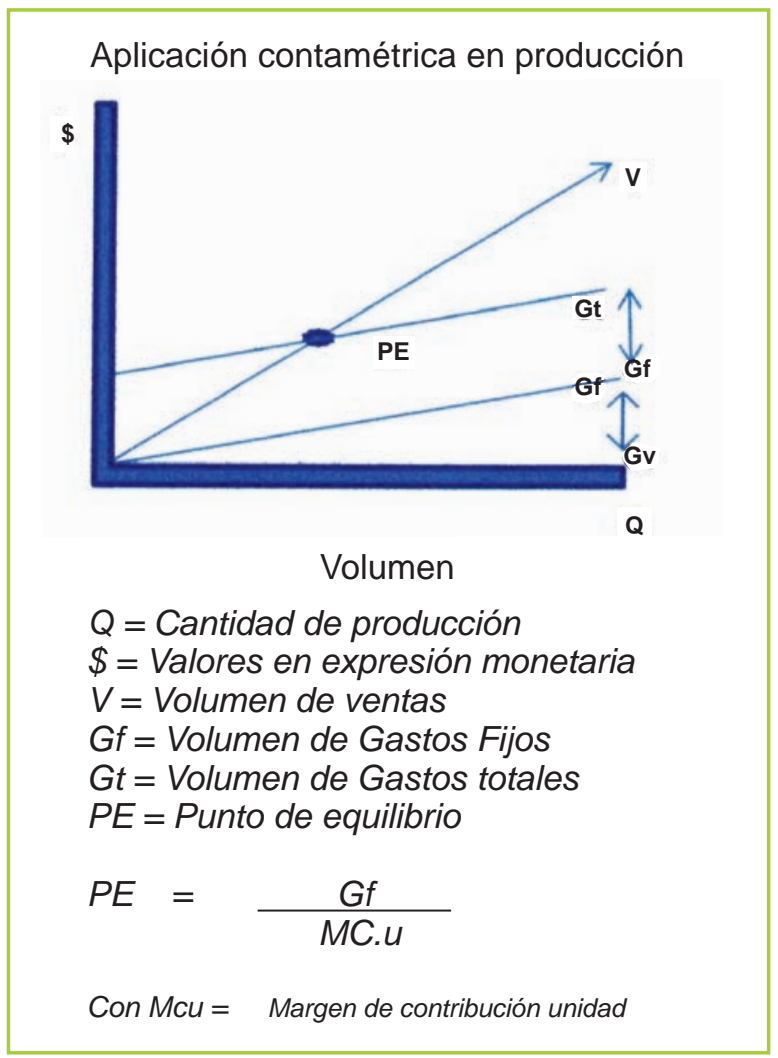

[Modelo basado en Horngren (Op. cit., p. 49)]

contametría. Sin embargo, se debe aclarar que en el terreno del precio, cuyo escenario es el mercado, al que concurren oferentes y demandantes, confluyen también varias disciplinas como la economía con la econometría, la sociología con la sociometría, la administración con la medición del capital humano y en su calidad de decisor de los eventos, entre otras, todas con la intención de hacer mediciones de impacto del individuo en la comunidad y en la sociedad, medir el riesgo de las inversiones, medir el impacto en el consumo, o bien la psicometría para medir el grado de motivaciones del consumidor frente a la forma de ofrecerle $x$ o y productos, etc.

\footnotetext{
Beltrán Jaramillo, Jesús Mauricio (1998). Indicadores de gestión. 2ª ed., 3R Editores, Ltda., Bogotá.

7 Horngren, Charles T. (1969). La contabilidad de costos en la dirección de empresas. Unión Tipográfica Editorial Hispanoamericana, México.
} 
El mercado (tangible o intangible) es el escenario en el que además de encontrarse oferentes y demandantes, también se encuentran múltiples disciplinas para estudiar el fenómeno socioeconómico ocurrido, por ocurrir, o el que no ocurrirá, y sus consecuencias, impactos, resultados, etc. Es el lugar en donde se manifiesta la interdisciplinariedad, la transdisciplinariedad, y en donde las escalas axiológicas deben contener principios o reglas que permitan formar decisiones (Bunge, 1972, p. 106) ${ }^{8}$.

\subsection{EXPLICACIÓN DE LA CONTAMETRÍA DINÁMICA}

La forma como ocurren los hechos socioeconómicos generadores de procesos contables se explica así (texto tomado con permiso escrito de los autores Avellaneda y otros, 2008, pp. 40 y 41$)^{9}$ :

1) "Los agentes sociales son las familias, las empresas y mediando entre ellas, el Estado; tales agentes interactúan en los mercados, los que son de dos clases: mercados de bienes y servicios y mercado de factores de producción (Brand, 2007, p. 508) ${ }^{10}$.

2) La economía se mueve debido a dos grandes fuerzas circulantes en forma cíclica: En un sentido circulan los bienes y servicios y en sentido contrario circulan los ingresos (Attiyeh, 1971, pp. 38 y 391 ${ }^{11}$.

3) En su movimiento los actos complejos generan procesos de información que pueden ser registrados, medidos y valorados por los métodos de la contametría.

4) Los procesos contables generan información necesaria para la toma de decisiones y el control de los organismos y la sociedad.

La contabilidad atiende un campo del conocimiento que consta de elementos conceptuales, elementos tecnológicos, elementos técnicos e información compleja emanada de los agentes sociales que intervienen en la creación, acumulación, desacumulación y destrucción de riqueza representada en el patrimonio.

Existen muchas formas de creación de riqueza, entre ellas la valorización de los elementos que componen el patrimonio (good will, licencias, patentes, valor económico agregado, plusvalía, etc.), la construcción y/o producción de bienes tangibles ya sea para uso del agente que los crea o para su venta. Cualesquiera sean las formas de creación de riqueza, esta se puede acumular en la masa patrimonial de quien la crea, o también puede destinarse al gasto.

Existen varias formas de acumulación del patrimonio; algunas de ellas son, a través de las utilidades obtenidas (ganancias), o de las ganancias ocasionales (premios, 0 herencias recibidas), entre otras.

\subsection{NIVEL MACRO DE LA CONTAMETRÍA}

Hasta ahora esta disertación ha explicado el método de la contametría y algunas de sus funciones en el nivel microeconómico. Pero se debe tener en cuenta que la sociedad, la economía, el Estado, son sistemas integrados en los que no puede funcionar el todo sin el funcionamiento de las partes.

Como se dijo antes, los agentes sociales son los individuos, las familias, las organizaciones, incluyendo en ellas las de propiedad del Estado y aquellas en las que tiene participación. Al sumar las funciones patrimoniales individuales, se obtienen las funciones macro, ya sean estas económicas, sociales o mixtas. Los fenómenos patrimoniales agregados que forman el nivel

8 Bunge, Mario (1972). Ética y ciencia. Tercera ed., Reidel Editores, Barcelona.

9 Avellaneda Rojas, Sara B.; Avellaneda Bautista, C.A. y Bermúdez Gómez, J.V. (2008). Estudio de la contabilidad por ciclos de operaciones financieras. Editorial Universidad Libre, Bogotá,.

10 Brand, Salvador Oswaldo (2007). Diccionario de economía. Plaza y Janés Editores Colombia, S.A., Bogotá.

1 Attiyeh, Richard; Lumsden, Keith y Bach, George L. (1971). Fundamentos de economía, macroeconomía. Trad. Alvaro Gurrea, Ediciones Deusto, Bilbao. 
macro también son sujetos de medición y valoración por la contametría.

En el nivel macro se tiene la contabilidad nacional - macrocontabilidad, en cuyo seno actúa la contametría; la contraloría que se hace a las finanzas del Estado trabaja sobre los resultados contamétricos para verificarlos, validarlos y con ellos validar sus propios procedimientos controlísticos, los que en últimas consecuencias también son funciones de la contabilidad; los sistemas de costos que fueron excluidos por la Ley 1314 de 2009 o de intervención económica, también son contables y es el subcampo contable que tiene más congruencia contamétrica.

Como resultado de esta investigación se ve con claridad que el desarrollo de la contametría permite integrar las disciplinas, definir los campos de acción de unas y otras, y la contabilidad puede integrarse alrededor de un factor que le permite fortalecer aquellas zonas que hasta ahora han sido descuidadas, y con las cuales puede sustentar el estatus de ciencia.

Hasta aquíqueda explicadoel método contamétrico; falta explicar el problema de investigación, a lo cual se dedica la siguiente sección.

\section{EL PROBLEMÁ LAS DINÁMICAS PATRIMONIALES}

\subsection{LA CONTAMETRÍA COMO SOPORTE DEL MÉTODO CIENTÍFICO EN LA DISCIPLINA CONTABLE}

Se ha dicho que la contametría es la teoría de las mediciones y la valoración del patrimonio de los agentes económicos, de nivel micro y de nivel macro. Pero al hablar de patrimonio se hace relación directa con el concepto de propiedad y como alguien debe ser el propietario de ese patrimonio, aparece casi por inercia la idea de propiedad privada. Sin embargo, evocando

\section{'Al sumar las funciones}

patrimoniales individuales, se

obtienen las funciones macro,

ya sean estas económicas,

sociales o mixtas. Los

fenómenos patrimoniales

agregados que forman el nivel

macro también son sujetos de

medición y valoración por

la contametría. 
"Precisamente el campo de la contabilidad que aboca el problema de la formalización cientifica es la contametría, que se ocupa de sistemativar el cuerpo teórico bajo la formalización matemática, lo cual incluye la notación matemática de los supuestos, axiomas, bipótesis, leyes, estructuras teóricas complejas y modelos que aplicados al campo de estudio de los fenómenos «conta», que giran alrededor de la dinámica de las masas patrimoniales en sus relaciones sociales implicadas y que pueden ser representadas por funciones matemáticas o en un nivel más complejo por, «modelos contamétricos». el axioma de la propiedad social, citado en la sección introductoria de este trabajo, surge la pregunta de investigación:

¿De qué manera la contametría permitiría abocar bajo el método científico la explicación de la dinámica patrimonial en una concepción social?

Responder esta pregunta es fundamental para aportar elementos clave en la consolidación del estatus científico de la contabilidad, que se debe soportar en la estructuración de una teoría general, y como uno de sus componentes, en una teoría general de la medición, cuyo campo de estudio es lo que se ha denominado contametría.

Para una respuesta integral, desde la perspectiva de sus diferentes facetas, proponemos examinar los aspectos que se reseñan a continuación, y que se constituyen en el tejido estructurante de un sistema de hipótesis que corresponden a los elementos conceptuales de una teoría general de la medición y la forma como se demuestra su aplicabilidad a los fenómenos contables:

- La explicación como elemento fundante de la teorización contable.

- Fundamentos epistemológicos de una teoría de la medición.

- La contametría como eje estructurante de una teoría de la medición.

- Elementos fundamentales de las dinámicas patrimoniales y su teoría explicatoria.

- Aplicaciones contamétricas en la realidad de las dinámicas patrimoniales de la economía colombiana: análisis de caso.

\subsection{ELEMENTOS FUNDAMENTALES DE LAS DINÁMICAS PATRIMONIALES Y SU TEORÍA EXPLICATORIA}

Una de las funciones de la ciencia es formular leyes y teorías científicas que expliquen los fenómenos objeto de estudio (Bunge, 1986). En la ciencia contable como ciencia social que es, estas leyes deben comprender y explicar las dinámicas patrimoniales, entendidas en su visón más amplia, es decir, incluyendo lo 
social implicado en esas dinámicas (Lopes de Sa, 1992; Franco, 1986). La generación de información referente a esas dinámicas patrimoniales y su medición y valoración son solo una parte de su deber ser como ciencia, muy importante porque permite describir los fenómenos objeto de estudio, pero no suficiente para obtener una verdadera comprensión y explicación de los mismos. Por ello la contametría debe aportar la matematización de las relaciones implicadas en esas dinámicas tanto económicas como sociales.

Es aquí donde empiezan a jugar un rol importante todas las herramientas matemáticas y estadísticas que ha desarrollado la humanidad y que han servido a todas las ciencias para formalizar su conocimiento y, para la contabilidad como ciencia, esto no es una excepción. García-Casella afirma: "para tener un conocimiento contable científico lo primero es haber reconocido un dominio y un conjunto de fenómenos en ese dominio, y lo segundo es haber ideado una teoría cuyos insumos y productos sean fenómenos en el dominio y cuyos términos puedan describir la realidad subrayable del dominio" (GarcíaCasella et al., 2001, p. 122).

Precisamente el campo de la contabilidad que aboca el problema de la formalización científica es la contametría, que se ocupa de sistematizar el cuerpo teórico bajo la formalización matemática, lo cual incluye la notación matemática de los supuestos, axiomas, hipótesis, leyes, estructuras teóricas complejas y modelos que aplicados al campo de estudio de los fenómenos "conta", que giran alrededor de la dinámica de las masas patrimoniales en sus relaciones sociales implicadas y que pueden ser representadas por funciones matemáticas o en un nivel más complejo por "modelos contamétricos", de los que se pueden derivar formalizaciones matemáticas en la construcción de las reglas que rijan el diseño de "sistemas contables específicos", como lo ha logrado Mattessich (2002) en su esquema de axiomatización que busca integrar todos los fundamentos que permitan construir una teoría general contable.

\subsection{FUNDAMENTACIÓN DE LOS MODELOS CONTÁMETRICOS PARA EXPLICAR LA DINÁMICA PATRIMONIAL}

\subsubsection{Antecedentes}

Nuestro fundamento parte de las bases teóricas establecidas por Lopes de Sá (1992) en el neopatrimonialismo, quien recorre un proceso epistemológico, iniciando por el restablecimiento de la esencia del fenómeno inmerso en el comportamiento patrimonial, criticando la forma plana de la tradicional representación contable a través de la partida doble, que solo refleja la fuente de los recursos y los efectos de esa operación como contrapartida, ocultando así muchos aspectos dimensionales y de correlaciones importantes. Reconoce que en el origen del hecho económico se produce una serie de acontecimientos simultáneos, que se corresponden con finalidades múltiples, lo que para Aristóteles significaba atribuir a los bienes - a la riqueza diferentes funciones, para la contabilidad es reconocer los tipos de relación entre medios y necesidades.

De esa manera reformula el concepto de patrimonio transformando la visión estática del resultado de la acumulación de riqueza, que es eminentemente descriptivo, para centrarlo bajo una perspectiva dinámica, explicativa de su origen y desarrollo, y correlativa a su finalidad: el conjunto de medios adecuados para satisfacer la necesidades hacendales, lo cual conlleva elementos de la ciencia normativa, que incluye, además de las relaciones de causaefecto, las relaciones entre fines-medio. Esto es lo que él define como funciones, entendidas como la forma de estudiar la adecuación de los medios para lograr ciertos resultados deseados, rescatando el análisis de las relaciones que se establecen entre diferentes alternativas de combinación de medios y los impactos que se alcanzan, permitiendo que la contabilidad como ciencia entre a desentrañar, comprender y explicar los fenómenos objeto de estudio, siendo éstos las dinámicas patrimoniales. 
El desarrollo teórico del enfoque neopatrimonialista ha establecido ocho tipos de funciones: las capacidades de pagar (liquidez), obtener ganancias (resultabilidad), mantener el equilibrio (estabilidad), tener vitalidad (economicidad), protegerse contra los riesgos (invulnerabilidad), ser eficientes o producir adecuadas utilidades (productividad), dimensionarse de modo competente (elasticidad), contribuir como agente para el entorno (sociabilidad), (Nepomuceno, 2008). Así, cuando ocurre una venta se afectan esas ocho dimensiones: la liquidez, los resultados, los riesgos, los niveles de pérdidas, la dimensión del patrimonio, la estructura patrimonial, las condiciones de supervivencia y la sociabilidad.

El desarrollo que proponemos en este artículo parte de las anteriores bases, pero complementa y amplía la estructura de las funciones agrupándolas en tres categorías, que recogen las visiones no solo de lo económico (primera categoría), sino rescatando el profundo contenido humano de la disciplina (segunda categoría de funciones alrededor del desarrollo humano y su máxima expresión, el conocimiento) y el hondo sentido social de su responsabilidad (tercera categoría). De igual manera recurrimos a la matematización a través de la representación mediante funciones matemáticas, que se integran sistémicamente en sistemas y subsistemas funcionales, bajo el esquema de modelización matemática, como expresión científica de las relaciones, interrelaciones y reciprocidades, que conforman lo que hemos denominado "modelos contamétricos", que buscan comprendery explicar las dinámicas patrimoniales. Se debe reconocer que es una primera aproximación, que propone las bases para ser desarrolladas, profundizadas, corregidas y mejoradas en posteriores estudios.

A continuación presentamos la estructura propuesta, partiendo de las hipótesisfundamentales que regulan todo el sistema y su modelamiento.

\subsubsection{Hipótesis}

1) Los enfoques teóricos que expliquen científicamente la dinámica patrimonial encuentran en los "modelos de comportamientos", diseñados desde la contametría, un buen soporte para representar, comprender y explicar las relaciones implícitas en los movimientos del capital.

2) Los modelos científicos teóricos de la contametría, permiten mostrar cuáles son las relaciones involucradas en los movimientos de capital, no solo desde la unidad individual de los negocios sino también desde los grandes agregados económicos, develando las relaciones sociales implícitas en la dinámica patrimonial.

3) El conjunto de modelos contamétricos organizados para explicar la esencia social de la dinámica patrimonial debe contemplar tanto las correlaciones generadoras de la efectividad, eficiencia y productividad en la generación y acumulación de capital, como también del manejo del recurso humano, con sus connotaciones de aporte a la productividad global y de su participación en esa generación de riqueza; así como del aporte de los valores agregados sociales como resultado de las formas de organización social, que contribuyen a la generación de la riqueza.

\subsubsection{Estructuración de los modelos}

A partir de las hipótesis planteadas se procede a estructurar un conjunto de relaciones o funciones patrimoniales, que materialicen la representación y explicación de la dinámica patrimonial en una concepción social. Ello exige tres grupos de funciones patrimoniales:

- Funciones patrimoniales que determinen los inductores de la productividad del capital.

- Funciones patrimoniales que determinen los inductores de productividad del talento humano.

- Funciones patrimoniales del valor agregado social y su contribución a la formación de la riqueza y su justa distribución.

A continuación se desarrollan bajo una concepción general las funciones globales que materializan la anterior clasificación, a manera de hipótesis, que deben ser contrastadas en un 
ejercicio de largo aliento y cuyo alcance en este texto se limitará a un caso concreto referente a uno de los aspectos que aboca la contametría: el impacto de los impuestos en la distribución de la riqueza.

\section{a) Funciones patrimoniales de la productividad del capital}

Las funciones de la productividad del capital deben estar orientadas a mostrar las relaciones entre las fuerzas determinantes de los tres elementos sustanciales para el desarrollo del patrimonio tanto a nivel micro como a nivel macro y sus mutuas interrelaciones: la rentabilidad, la liquidez, el crecimiento y su reflejo en la productividad del capital (Amat, 1999; Álvarez, 2000). A continuación se presentan las respectivas funciones.

\section{- Rentabilidad}

(1) Valor económico agregado (EVA) = utilidad antes de intereses y después de impuestos (UAIDI) - valor contable del activo (VCA)*costo promedio de capital (CPM).

$\mathrm{EVA}=\mathrm{UAIDI}-\left(\mathrm{VCA}{ }^{*} \mathrm{CPM}\right)$

(2) Ingresos $(I)=[(P)(Q)$

(3) UAIDI $=$ ingresos (I) - costos totales (CT) UAIDI $=(I)-(C T)$.

UAIDI: utilidad antes de intereses y después de impuestos

P: precio $Q$ : cantidades

(3.1) índice de rentabilidad sobre el patrimonio $(\mathrm{IRP})=$ UAIDI / patrimonio $(\mathrm{P})$

(3.2) índice de rentabilidad sobre activos (IRA) $=$ UAIDI / activo total (AT)

(3.3) índice de rentabilidad sobre ventas $=$ UAIDI / ventas (V)

- Liquidez

(4) kapital neto de trabajo: KNT= activo cte (AC) - pasivo cte (PC)

(5) índice de liquidez (IL): AC / PC

(6) índice de endeudamiento (IE): pasivo con terceros (PCT) / activo total (AT)

- Crecimiento $g=(I R P){ }^{*}$ tasa de retención de utilidades $(\mathrm{TRU})=(\mathrm{IRP}) *(\mathrm{TRU})$ $\mathrm{g}$ : tasa de crecimiento
${ }^{66}$ Las funciones de la

productividad del capital

deben estar orientadas a

mostrar las relaciones entre

las fuerzas determinantes de

los tres elementos sustanciales

para el desarrollo del

patrimonio tanto a nivel

micro como a nivel macro $y$

sus mutuas interrelaciones: la

rentabilidad, la liquidez̧, el

crecimiento y su reflejo en la

productividad del capital." 


\section{${ }^{66}$ Las funciones de la productividad del talento bumano deben estar orientadas a mostrar las relaciones entre las fuerzas determinantes de los elementos sustanciales para el desarrollo del talento bumano, fundamentados en la gestión del conocimiento.'}

- Índice de productividad del kapital (IPK) $[\alpha]^{* i ́ n d i c e ~ d e ~ I n v e r s i o ́ n ~(I I V) ~}+\alpha 2{ }^{*}$ índice de rentabilidad de la inversión (IRI) $+\alpha 3^{*}$ índice de endeudamiento (IE) $+\alpha 4$ *índice de liquidez $(\mathrm{IL})] * g$

$\Rightarrow \quad\left|P K=[\alpha]^{*}\right|\left|V+\alpha 2^{*}\right| \mathrm{RI}+\alpha 3^{*} \mid \mathrm{E}+$ $\left.\alpha 4^{*} \mid \mathrm{L}\right]^{*} \mathrm{~g}$

$\alpha 1=$ ponderado del índice de inversión

$\alpha 2=$ ponderado de la rentabilidad de la inversión

$\alpha 3$ = ponderado del índice de endeudamiento $\alpha 4=$ ponderado del índice de liquidez

\section{b) Funciones patrimoniales de la productividad del talento humano}

Las funciones de la productividad del talento humano deben estar orientadas a mostrar las relaciones entre las fuerzas determinantes de los elementos sustanciales para el desarrollo del talento humano, fundamentados en la gestión del conocimiento (Bueno, et al., 2011).

- Remuneración

Remuneración del factor trabajo $(\mathrm{RFT})=\Sigma$ salarios (S)

Índice de remuneración del trabajo $=(S) /$ EVA

- Bienestar

Este es un factor importante en el desarrollo organizacional, pero es una visión que ha sido descuidada desde la perspectiva de la contabilidad. Existen diversos modelos que se orientan a evaluar este factor, pero casi nunca se han vinculado con la contabilidad de una organización. Tales enfoques se estructuran tanto desde la mirada micro como desde la mirada macro.

A manera de ejemplificación, queremos mostrar la aplicabilidad de la metodología del Índice de bienestar económico y social (IBES), construido por el economista Juan Alarcón (2008), con la cual se busca medir la situación económica y social de la población 
de una localidad, agrupando en tangibles, intangibles, individuales y colectivos, los bienes poseídos por una persona y así obtener 4 macro-indicadores que sumados sitúan al grupo de personas analizadas en una escala de 0 a 100 o índice IBES. Si bien este indicador fue diseñado pensando en una medición macro de una localidad, región o país, creemos que también es aplicable en el interior de una empresa tomando como población al grupo humano que la integra y de allí derivar una medida del bienestar humano en el interior de la misma.

Esta medición debería generar un estado contable que integre información cualitativa y cuantitativa, que agregaría mucho valor a la información contable, generada desde el ente económico, pero integrando una visión más humana del desarrollo empresarial, soportada en la contabilidad.

Este modelo se integra en una matriz del bienestar social de una comunidad, en este caso de la comunidad humana que conforma la empresa, la cual, según la propuesta de Alarcón, distribuye los bienes o componentes distinguiendo los aspectos tangibles (materiales) y los intangibles (inmateriales) por una parte, y los individuales (personales) y colectivos (comunitarios) por otra. Dado que el IBES es la suma de estos componentes, para llegar a un resultado hay que atribuirles una ponderación, de forma que la suma sea 100\%. Esta distribución sería responsabilidad del grupo gerencial en consenso con los empleados, pero a manera de ejemplo se presenta la siguiente matriz de distribución (Figura 1).

Traducir esta matriz en procesos de medición de cada categoría de variables y la definición de cada una de estas, que deben conformar la respectiva categoría, es un problema de teorización contamétrica que exige la definición de los postulados que orienten su estudio científico, así como las hipótesis que soporten una teoría alrededor de este concepto, lo que finalmente se debe traducir en métodos de captación, registro, medición, valoración y representación, que debe ser abordado por la ciencia contable, que así rebasa el objeto únicamente económico de la medición del patrimonio, pues este debe estudiarse en forma integral, incluyendo una visión social, que están reclamando los implicados en el desarrollo de la disciplina contable.

- Capacitación y desarrollo del conocimiento = gestión del conocimiento

Este componente se ha vuelto vital en los procesos de captación, registro, medición, valoración y representación de las dinámicas del patrimonio, pero su desarrollo teórico es muy reciente, lo cual exige un gran esfuerzo de la disciplina para integrarlo a la teoría contable y a su desarrollo contamétrico. Presentamos a continuación una función de autoría propia, que debe ser sometida a

Figura 1. Matriz de distribución de componentes del IBES.

\begin{tabular}{|l|l|l|}
\hline \multicolumn{1}{|c|}{ IBES (100\%) } & \multicolumn{1}{|c|}{ Bienes individuales (70\%) } \\
$\begin{array}{l}\text { Bienes } \\
\text { tangibles (50\%) }\end{array}$ & $\begin{array}{l}\text { Económicos 40\% } \\
\text { Ingresos (50\%) } \\
\text { Patrimonio (30\%) } \\
\text { Salud (20\%) }\end{array}$ & $\begin{array}{l}\text { Públicos 10\% } \\
\text { Servicios públicos (50\%) } \\
\text { Salubridad (50\%) }\end{array}$ \\
\hline $\begin{array}{l}\text { Bienes } \\
\text { intangibles (50\%) }\end{array}$ & $\begin{array}{l}\text { Personales 30\% } \\
\text { Estudios generales (40\%) } \\
\text { Formación profesional (60\%) }\end{array}$ & $\begin{array}{l}\text { Comunitarios 20\% } \\
\text { Seguridad (60\%) } \\
\text { Derechos humanos (40\%) }\end{array}$ \\
\hline
\end{tabular}

Fuente: Tomado de Alarcón (2008). 
prueba para demostrar su bondad, lo cual no es el alcance de este texto.

Índice de gestión del conocimiento (IGC) = $\mu 1 *$ índice de formación intelectual (IFI) $+\mu 2 *$ índice de productividad del trabajo (IPT) + $\mu 3^{*}$ índice de aprendizaje $(\mathrm{IA})+\mu 4^{*}$ índice de innovación (II) $+\mu 5^{*}$ índice de acumulación de capital intelectual (IAKI).

$\Rightarrow \mathrm{IGC}==\mu 1^{*}(\mathrm{IFI})+\mu 2^{*}(\mathrm{IPT})+\mu 3^{*}(\mathrm{IA})+$ $\mu 4^{*}(\mathrm{II})+\mu 5^{*}(\mathrm{IAKI})$

$\mu 1=$ ponderado de formación intelectual

$\mu 2=$ ponderado de productividad del trabajo

$\mu 3=$ ponderado de aprendizaje

$\mu 4=$ ponderado de innovación

$\mu 5=$ ponderado de capital intelectual

El desarrollo e implementación de esta función, en la forma presentada o en cualquier otra, que represente este componente de las dinámicas patrimoniales, debe ser el faro que guíe y estructure la teorización correspondiente, bajo el enfoque de la contametría, aspecto que se encuentra en forma fragmentaria y no integrado en un marco de la teoría general contable, desde el paradigma de la complejidad, que es una propuesta por desarrollar y que aparece subyacente en este artículo.

\section{c) Funciones patrimoniales del valor agregado social}

Las funciones del valor agregado social deben estar orientadas a mostrar las relaciones entre las fuerzas determinantes de los elementos sustanciales para el desarrollo social de las comunidades que conforman el entramado social de un país y sobre los cuales tienen influencia las actividades de la empresa (Franco, 2003). Veamos las variables organizadas en tres categorías, con las respectivas funciones:

- Contribuciones al desarrollo integral de las comunidades

Este componente se puede apoyar en el modelo de IBS de Alarcón expuesto anteriormente, pero esta vez sí orientado al conglomerado social en que interactúa la empresa y sobre la cual tiene influencia. Ello exigiría el cálculo del IBS de ese conglomerado, pero cuyo resultado se debe integrar a una función que nos permita medir el aporte que hace la empresa a ese indicador. Nuestra función propuesta sería la siguiente:

Índice de contribución al desarrollo integral de las comunidades $(I C D I C)=\beta 1^{*}$ índice de contribución a la generación de empleo (ICGE) + $\beta 2 *$ índice de contribución al desarrollo tecnológico del sector (ICDTS) + $\beta 3^{*}$ índice contribución al bienestar social de la comunidad (ICBSC) $+\beta 4^{*}$ índice de contribución a la acumulación del capital social de la comunidad (ICACS)

$\Rightarrow \quad I C D I C==\beta 1^{*}(I C G E)+\beta 2^{*}($ ICDTS $)+$ $\beta 3^{*}\left(\right.$ ICBSC) $+\beta 4^{*}($ ICACS $)$

$\beta 1=$ ponderado contribución a la generación de empleo

$\beta 2$ = ponderado de contribución al desarrollo tecnológico del sector

$\beta 3=$ ponderado de contribución al bienestar social de la comunidad

$\beta 4=$ ponderado de contribución a la acumulación de capital social de la comunidad

- Contribuciones al mejoramiento del medio ambiente

Índice de contribución al medio ambiente $(\mathrm{ICMA})=€ 1$ * índice de producción limpia (IPL) $+€ 2 *$ índice de manejo de desechos (IMD) $+€ 3^{*}$ índice de manejo de contaminantes (IMC).

$\Rightarrow I C M A=€ 1^{*}(I P L)+€ 2 *(I M D)+$ $€ 3^{*}(\mathrm{IMC})$

$\Rightarrow € 1=$ ponderado del índice de producción limpia.

$\Rightarrow € 2=$ ponderado del índice de manejo de desechos.

$\Rightarrow € 3=$ ponderado del índice de manejo de contaminantes. 
- Contribuciones a la redistribución de la riqueza

Índice de contribución a la redistribución de la riqueza $\left(\right.$ ICRR) $=\# 1^{*}$ índice de contribución al medio ambiente (ICMA) $+¥ 2^{*}$ índice de contribución al desarrollo integral de las comunidades (ICDIC) $+¥ 3^{*}$ índice de donaciones (ID) $+¥ 4 *$ índice de contribuciones al fisco (ICF)

$\Rightarrow I C R R=¥]^{*}(I C M A)+¥ 2^{*}(I C D I C)+$ $¥ 3 *(I D)+¥ 4$ (ICF)

$\Rightarrow \# 1=$ ponderado del índice de contribución al medio ambiente.

$\Rightarrow ¥ 2=$ ponderado del índice de contribución al desarrollo de las comunidades. $\Rightarrow ¥ 3=$ ponderado del índice de donaciones.

$\Rightarrow ¥ 4=$ ponderado del índice de contribuciones al fisco.

Dentro de esta última categoría es donde el presente artículo se propone elaborar una aplicación concreta, lo cual abocaremos en la última sección del mismo, como un análisis de caso. Sin embargo, el enfoque sistémico y holístico de todo el modelo presentado debe ser desarrollado en forma modular, hasta lograr su integración total en un solo modelo que incluya todas las funciones diseñadas en los apartados anteriores. Veamos a continuación cuáles serían los criterios de esa integración.

\section{d) Integración de todo el modelo}

Teleológicamente, el modelo busca satisfacer necesidades sociales entre las cuales están las del empresario, pero además están las de los empleados, las de la sociedad en su conjunto, las de las comunidades específicas a las que atiende la empresa, o en las que influye de alguna manera, como es el caso de los clientes, proveedores, comunidades locales, el Estado, el mismo medio ambiente, lo cual integra las diferentes visiones y necesidades, bajo un enfoque más armónico, recurriendo al paradigma de la complejidad desde un enfoque sistémico. Esta estructura ampara las diferentes funciones
${ }^{66}$ Las funciones del valor agregado social deben estar orientadas a mostrar las relaciones entre las fuerzas determinantes de los elementos sustanciales para el desarrollo social de las comunidades que conforman el entramado social de un país y sobre los cuales tienen infuencia las actividades de la empresa. 
${ }^{6}$ El esquema asegura que cada subsistema influya sobre los demás, en un esquema de recursividad y bajo el principio de doble bucle, como lo propone el paradigma de la complejidad. Esto lo estudia el modelo neopatrimonialista, bajo los paradigmas de la satisfacción de las necesidades (eficacia) y de la correlación de eficacias que denomina como interacción perfecta. patrimoniales presentadas y garantiza la eficacia desde lo particular de cada interesado, pero también desde lo social y comunitario, desde una perspectiva más equilibradora.

Bajo el enfoque sistémico, el conjunto de funciones se han diseñado de tal manera que se interrelacionan, en forma tal que cualquier decisión se puede evaluar desde cada una de las categorías, pero también de todo el sistema representado, lo cual asegura mantener la efectividad, eficiencia, economicidad y productividad de todo el modelo. Es finalmente la última categoría (representada en las funciones patrimoniales de generación de valor agregado social), la que se puede constituir en la función o subsistema de funciones objetivo de optimización, logrando la integración global del sistema representado y su equilibrio general.

El esquema asegura que cada subsistema influya sobre los demás, en un esquema de recursividad y bajo el principio de doble bucle, como lo propone el paradigma de la complejidad. Esto lo estudia el modelo neopatrimonialista, bajo los paradigmas de la satisfacción de las necesidades (eficacia) y de la correlación de eficacias que denomina como interacción perfecta.

En la sección siguiente se presenta el caso aplicativo alrededor de las funciones relativas al índice de contribución al fisco, que hacen parte de la categoría de funciones de contribución a la redistribución de la riqueza, como uno de los componentes de las funciones patrimoniales de generación de valor agregado social.

\section{e) Aplicaciones contamétricas en la realidad de las dinámicas patrimoniales de la economía colombiana}

El planteamiento de esta sesión va dirigido a exponer por medio de un ejemplo de tipo fiscal, la manera como la contametría explica las dinámicas patrimoniales desde una concepción social, para lo cual se toma como base el trabajo de Avellaneda (201 1, pp. 298 a 
302) $)^{12}$, con autorización del autor. Se seleccionó el tipo de caso, teniendo en cuenta que uno de los aspectos más relacionados con la concepción social son los impuestos, que estos son resultado de la dinámica del patrimonio y su producto es la fuente principal de recursos del Estado y su finalidad es la redistribución del bienestar en la sociedad por medio de los servicios del Estado.

\section{f) Funciones para analizar el desarrollo sostenible (DS)}

Para demostrar la aplicación contamétrica de las dinámicas patrimoniales desde la concepción social, tomamos la siguiente función desarrollada por Avellaneda (Op. cit.).

$D s=\sqrt[2]{P t\left(\frac{R}{P_{p}} / I_{c}\right)}$

Con $D s$ = índice de desarrollo sostenible

$P t=$ población total

$R=$ ingreso (o renta líquida) susceptible de ser capitalizado o invertido en factores de desarrollo $P p=$ población pobre

Ic $=$ ingreso corriente

Las posibilidades en la relación siempre serán:

a) Ds > Ic (R/P), dado un componente fiscal de alta eficiencia (Ef) y eficacia

b) $D s=I c(R / P)$, dado un componente fiscal de normal eficiencia y eficacia.

c) Ds < I c $(R / P)$, dado un componente fiscal de baja eficiencia y baja eficacia.

d) Eficiencia fiscal (Ef) y eficacia son variables cualitativas compuestas por decisiones de los gobernantes y las necesidades sociales por solucionar.

El ingreso corriente del Estado, enfatizando la aplicación al gasto público y a la inversión, se expresa por medio de la siguiente función:
IC $=\frac{\left[\frac{A}{F 1}\right]}{F 2}$

Donde:

Ic $=$ ingreso corriente

$A=$ impuesto aportado por un solo contribuyente de una comunidad

$F 1$ = factor de participación de $A$ en el total de impuestos que aporta la comunidad

$F 2$ = factor de participación de la comunidad en el ingreso corriente de la Nación

Demostremos el modelo antes planteado, por medio de las siguientes funciones:

a) El impuesto como ingreso corriente de la Nación.

b) El gasto público como depurador de la renta para obtener el ingreso susceptible de aumentar el patrimonio, que en esta propuesta viene a ser la magnitud aplicable al desarrollo.

c) El factor de desarrollo sostenible es el índice numérico con el cual se puede cuantificar e interpretar la medición de desarrollo que tenga el país en un período determinado.

\section{f) Impuesto como ingreso corriente de la Nación}

I es el resultado de dividir Ds. por el cociente de la relación riqueza - pobreza.

$$
\mathrm{I}=\frac{\mathrm{Ds}}{\frac{\mathrm{R}}{\mathrm{P}}}
$$

En esta función, la variable (I) o impuesto se refiere al acumulado macro de ingreso corriente susceptible de incrementar la riqueza, o aplicarla a la inversión. Representa el ingreso corriente, después de deducir el gasto público. Dicha variable es resultado de dividir la magnitud de desarrollo sostenible (Ds) por el cociente que resulta de la relación de las variables riqueza y pobreza.

12 Avellaneda, C.A. (2011). Riqueza, pobreza e impuestos como factores de desarrollo. Criterio Libre, N ${ }^{\circ} 15$, diciembre 201 1, Universidad Libre, Bogotá. 
Siendo los impuestos la parte de la riqueza que los gobernados trasladan al Estado en su calidad de súbditos, la riqueza es una magnitud susceptible de ser mantenida o incrementada por medio de su propia dinámica, así como también de mejorar el nivel de vida de la población; ese resultado se denomina desarrollo (Brand, Op. cit., p. 250). Es desarrollo sostenible (Ds) si se mantiene durante muchas generaciones.

En esta investigación se ve el desarrollo sostenible con un comportamiento similar al de aquellas unidades económicas que obtienen utilidades pero solo distribuyen a sus socios una parte de ellas y con la otra parte incrementan su patrimonio. Al cabo de muchos ejercicios operacionales habrán crecido, según sea la cantidad capitalizada.

Desarrollo no es lo mismo que crecimiento; sin embargo, en este ejercicio lo asimilaremos a crecimiento, con el fin de hacer comprensible la ilustración de la medición contamétrica en aspectos de las dinámicas patrimoniales desde la concepción social. El análisis se asume con solo las variables ingreso y gasto público, Ceteris paribus del método económico, para las demás variables.

\section{g) Aplicación práctica}

Si en un período analizado el agente $J$ tributó $\$ 64.533 .750$ (cifra real tomada de los archivos con consentimiento del contribuyente), monto que equivale a tres cienmilésimas (3/100.000) -estimado-, del total de impuestos que paga la comunidad (del ente territorial), y esta magnitud equivale a 2,5\% del total de aportes (impuestos) de la sociedad, ¿̇cuánto es el ingreso corriente de la Nación? (Tabla 1).

Se obtuvo por medio de un sencillo procedimiento contamétrico, y demuestra la incidencia de un solo agente en el contexto financiero de la Nación.

La explicación contamétrica de las dinámicas patrimoniales desde una concepción social se pueden ver al analizar la redistribución del ingreso corriente, en proporción de las necesidades de la comunidad, así:

Si el promedio de gasto público es 66,25\% del ingreso corriente (Congreso de la República, 2000) ${ }^{13}$, ¿̇cuánto es el ingreso susceptible de ser ahorrado o invertido (la)?

Para la explicación, asimilamos la dinámica operativa del Estado con la de una organización micro, cuya dinámica del patrimonio (operaciones) genera ingresos, incurre en gastos y obtiene rentas susceptibles de aumentar el patrimonio.

La fórmula para calcular el ingreso susceptible de ser ahorrado (la), es la siguiente: la $=\mathrm{lc}-$ $66,25 \%$ (Ic)

\section{Tabla 1. Cálculo del ingreso corriente de la Nación en el período X.}

\begin{tabular}{|l|r|}
\hline \multicolumn{1}{|c|}{ Detalle } & Magnitudes \\
\hline Impuesto del contribuyente (A) & $\$ 64.533 .750 .000$ \\
\hline Factor de participación en el ingreso local (F1) & 0,00003 \\
\hline Total impuestos de la comunidad. (A/F1) & $\$ 2.151 .125 .000 .000 .000$ \\
\hline Proporción en ingreso cte. de la Nación. (F2) & $2,50 \%$ \\
\hline TOTAL INGRESO CORRIENTE DE LA NACIÓN. [(A/F1)/F2] & $\$ 86.045 .000 .000 .000 .000$ \\
\hline
\end{tabular}

Respuesta. El ingreso corriente de la Nación es \$86,04 billones de pesos.

13 Congreso de la República. Ley 617 de 2000, Artículo 6. Reforma a la Ley de Presupuesto -de Colombia-, y otras Disposiciones. 
Diremos entonces que a los ingresos brutos restamos el monto de gasto público (GP) para obtener el monto de renta susceptible de incrementar la riqueza.

Con base en la Ley de presupuesto antes citada, el ingreso corriente se distribuye para gasto público y para ahorro o inversión, como se muestra en la Tabla 2.

Siguiendo a Avellaneda B. et al., "En materia tributaria se define Renta como el ingreso susceptible de aumentar la riqueza de quien la percibe" (Avellaneda, 2011 , p. 101) 14. En consecuencia, si la Nación percibe una renta de \$29,04 billones, susceptibles de incrementar la riqueza nacional, puede hacer inversiones hasta por ese monto.

\section{h) Asignación}

Para la asignación de recursos en la distribución del resultado social, se tiene en cuenta una población de 46.714.251 habitantes, a la fecha 26 de septiembre de 2012 (DANE, 2012, hora 1:20 p.m.). $)^{15}$.

Utilizando los porcentajes citados en el trabajo de Avellaneda (Op. cit.), 45\% de la población colombiana tiene situación de pobreza: 21.021 .413 habitantes.

De ellos, según Carranza (citado por Avellaneda), $16 \%$ está en pobreza extrema -indigencia- (45\% X
$16 \%=7,2 \%)$, es decir, la cantidad de 3.363.426 habitantes están en indigencia, y según Friedman (1991, p. 388)16, citando a Pigou, "el deseo final del público no es, en última instancia, ahorrar, sino contar con una cierta cantidad de riqueza". Deseo propio de ricos, pobres e indigentes.

\section{i) ¿Cómo es la distribución de la riqueza?}

Siguiendo el método contamétrico, para explicar las dinámicas patrimoniales desde la concepción social:

"si se distribuye la riqueza $(R)$ por medio de un factor que varía en proporción directa con la variación del ingreso; y suponiendo también un factor para la población no pobre, y otro mayor para la población pobre, se obtendrá el factor de desarrollo sostenible" (Avellaneda et al.)

Si se tiene en cuenta la metodología del gobierno colombiano plasmada en el artículo $9^{\circ}$ del Decreto 1939 de 2001:

"Los recursos serán distribuidos por el Departamento Nacional de Planeación en proporción directa a la población de los departamentos y municipios (...) y a su eficiencia fiscal y administrativa, e inversamente proporcional a su grado de desarrollo (...)"

El precepto tiende a la justicia pero, desde el principio de consumo, los pobres no ahorran

Tabla 2. Distribución del ingreso (con aproximación a la centésima más cercana).

\begin{tabular}{|l|l|}
\hline \multicolumn{1}{|c|}{ Detalle } & \multicolumn{1}{c|}{ Valores } \\
\hline Ingreso corriente (Ic) & $\$ 86,04$ billones \\
\hline Gasto público $(66.25 \%)(66,25 \%$ XIc) & $\$ 57,00$ billones \\
\hline Diferencia para ahorro o inversión 8la) $=(\mathrm{Ic}-\mathrm{Gp})$ & $\$ 29,04$ billones \\
\hline
\end{tabular}

Fuente: Elaboración de los autores utilizando procedimiento explicado por Avellaneda (Op. cit.).

14 Avellaneda B., C.A. (2011). Fundamentación y normativa tributaria. Editorial Universidad Libre, Bogotá.

15 DANE. Reloj Poblacional, 29 de septiembre de 2012, hora 1:20 p.m.

16 Friedman, op. cit. 
porque los pocos ingresos que obtienen los consumen, es decir, no tienen capacidad de ahorro, reflexión esta que se tiene en cuenta para la distribución de la riqueza.

Con base en la política de Estado antes citada, asumiremos que los factores de distribución son $25 \%$ para la población no pobre y $75 \%$ para la población pobre. En consecuencia, para ahorro o inversión social, a la población le corresponde una asignación como se muestra en la Tabla 4.
La forma de distribuir el resultado social para que la comunidad se beneficie es por medio de las políticas públicas para llevar a cabo los fines esenciales del Estado (servicios de salud, vivienda, educación, otros).

Queda así dada la explicación contamétrica de las dinámicas patrimoniales desde una concepción social, sin ser la única, pues existen múltiples aspectos de hacer análisis contamétrico para estudiar las dinámicas patrimoniales en función social.

Tabla 4. Distribución de la riqueza.

\begin{tabular}{|l|c|c|c|}
\hline \multicolumn{1}{|c|}{ Categoría } & $\%$ & Población & Asignación de la renta (billones de pesos) \\
\hline Población rica & 55 & 25.692 .938 & 15,97 \\
\hline Población pobre & 37,8 & 17.657 .987 & 10,98 \\
\hline Población indigente & 7,2 & 3.363 .426 & 2,09 \\
\hline TOTALES & 100 & 46.714 .251 & $\$ 29,04$ billones \\
\hline
\end{tabular}

Fuente: Elaboración propia, basado en la metodología publicada por Avellaneda (Op. cit.).

\section{CONCLUSIONES}

- La medición es un tema que hasta el momento de publicar este trabajo no ha sido resuelto satisfactoriamente por las disciplinas sociales; no obstante, la contabilidad se ha encargado desde su origen a las funciones de medición de los patrimonios, sin que los contables se hayan preocupado en forma rigurosa de hacer episteme en esta área del conocimiento.

- Las mediciones y valoración de los patrimonios de los agentes sociales han sido atendidos y enfocados a la propiedad personal, pero solo hasta finalizando el siglo XX se empieza a mirar desde la óptica social y es cuando aparece la crítica sobre las falencias de fundamentación científica para la contabilidad. Progresivamente va cambiando la visión de una contabilidad eminentemente técnica hacia una contabilidad con características de ciencia social aplicada.

- La crítica sobre mediciones, valoración y concepción social lleva a la necesidad de investigardesdeesta óptica, formularpropuestas, debate y soluciones empíricas; estudios que ya empiezan a ser protagónicos bajo el concepto de contametría (o contabilometría, como la han denominado en Brasil).

- El método contamétrico, al tener como objeto el patrimonio como representación de la riqueza, permite el análisis multidimensional, como quedó demostrado en el presente trabajo.

- La contametría atiende la problemática de medición y valoración de los patrimonios en su estado estático como también en su estado dinámico, permite la representación conceptual y ontológica de su objeto, es coadyuvante de la interdisciplinariedad y la transdisciplinariedad y es factor integrador, en su calidad de órgano esencial, para la existencia de la ciencia contable.

- La contametría explica científicamente las dinámicas patrimoniales desde una concepción social, como quedó demostrado en el trabajo que aquí se publica. 
Alarcón, Juan J. (2008). IBES Versión Beta 02.08 Limmat Stiftung, Zurich, consultado en http://www.limmat.org/filelinks/IBES-BenSocBeta02-08.pdf

Álvarez Piedrahita, Iván (2000). "Finanzas estratégicas y creación del valor", Financial Publishing.

Amat, Oriol (1999). EVA Valor Económico Agregado, Editorial Norma, Bogotá, D.C.

Attiyeh, Richard; Lumsden, Keith; y Bach, George L. Fundamentos de Economía, Macroeconomía, trad. Alvaro Gurrea, Ediciones Deusto, Bilbao, 1971.

Avellaneda B., C.A. Riqueza, pobreza e impuestos como factores de desarrollo. En Criterio Libre, $N^{\circ}$ 15, diciembre 2011, Universidad Libre, Bogotá.

Avellaneda B., C. A. Fundamentación y normativa tributaria. Editorial Universidad Libre, Bogotá, junio 2011.

Avellaneda Rojas, Sara B.; Avellaneda B., C.A. y Bermúdez Gómez, J. V. Estudio de la contabilidad por ciclos de operaciones financieras. Editorial Universidad Libre, Bogotá, 2008.

Beltrán Jaramillo, Jesús Mauricio. Indicadores de gestión, 2a ed., 3R Editores Ltda., Bogotá, 1998.

Brand, Salvador Oswaldo. Diccionario de Economía. Plaza y Janes Editores Colombia, S.A., Bogotá, 2007.

Bueno, E., Longo, M., Merino, C., Murcia, C., Real del, H. y Salmador, M. (2011). Propuesta de nuevo modelo Intellectus de medición, gestión e información del capital intelectual, Madrid: CIC, Universidad Autónoma de Madrid.
Bunge, Mario (1986). La ciencia, su método y su filosofía. Bogotá: Ediciones Nacionales.

Bunge, Mario. Ética y ciencia, tercera ed., Reidel Editores, Barcelona, 1972.

Castaño Tamayo Ramón Abel. Ideas económicas mínimas, $8^{a}$ ed., Editorial Bedout, S.A. Medellín, 1979.

Coelho Da Rocha, Luiz Fernando. Aportes sobre doctrina científica del neopatrimonialismo contable. En: Revista Internacional LEGIS de Contabilidad y Auditoría, No 20, Bogotá, diciembre 2004.

Congreso de la República. Ley 617 de 2000, Artículo $6^{\circ}$. Reforma a la Ley de Presupuesto de Colombia, y otras disposiciones.

DANE. Reloi poblacional. 29 de septiembre de 2012, hora 1:20 p.m.

Diccionario de contabilidad y finanzas. Editorial Cultural S.A., Madrid, España, 1999.

Franco Ruiz, Rafael (2003). "Hacia un modelo de contabilidad integral". En: Revista Internacional Legis de Contabilidad y Auditoría, No. 15, julio-septiembre 2003.

Franco Ruiz, Rafael (2010). Reflexiones contables, teoría, regulación, educación y moral, tercera ed., Universidad Libre de Colombia, Bogotá, D.C.

García Casella, Carlos Luis y Rodríguez de Ramírez, M.C. (2001). Elementos para una teoría general de la contabilidad. Buenos Aires, Editorial La Ley S.A.

Horngren, Charles T. La contabilidad de costos en la dirección de empresas. Unión Tipográfica Editorial Hipanoamericana, México, 1969. 
Lopes de Sá, Antonio (1992). "Fundamentos lógicos de la teoría de las funciones sistemáticas del patrimonio hacendal". En revista Cuadernos, 23, 1992, consultado en: http://externos.uma.es/cuadernos/pdfs/ pdf492.pdf.

Mattesich, R. (2002). Contabilidad y Métodos Analíticos: Medición y proyección del Ingreso y la Riqueza en la Microeconomía y Macroeconomía. Buenos Aires. Editorial La
Ley. traducción de García Casella, C. L. y Rodríguez de Ramírez, M.C. del original en inglés editado en 1964 por Richard D. Irwin Inc. Homeword Illinois, USA.

Nepomuceno, V. (2008). Teoría da Contabilidades, Curitiba: Juruá.

Schmidt, Stephen J. Econometría, trad. De Pecina y Pineda, Editorial McGraw-Hill, México, 2005. 